\title{
Effect of Tumbling Marination on Marinade Uptake of Chicken Carcass and Parts Quality
}

\section{-Author(s)}

\section{U-chupaj J' \\ Malila $Y^{\prime \prime}$ \\ Petracci M"II \\ Benjakul S' \\ Visessanguan $\mathrm{W}^{\prime \prime}$}

Department of Food Technology, Faculty of Agro-Industry, Prince of Songkla University, Hat Yai, Songkhla 90112, Thailand

" National Center for Genetic Engineering and Biotechnology (BIOTEC), 113 Thailand Science Park, Phahonyothin Rd., KhlongNueng, KhlongLuang, Pathum Thani12120, Thailand

III Department of Agricultural and Food Sciences, Alma Mater Studiorum University of Bologna, 47521 Cesena (FC), Italy

\section{-Mail Address}

Corresponding author e-mail address Wonnop Visessanguan

National Center for Genetic Engineering and Biotechnology (BIOTEC), 113 Thailand

Science Park, Phahonyothin Rd., Khlong

Nueng, Khlong Luang, Pathum Thani

12120, Thailand

Tel: (+66) 21178031

Email: wonnop@biotec.or.th

\section{-Keywords}

Marination, chicken carcass, marinade uptake, water-holding capacity, cut-up meat.

\section{ABSTRACT}

The objectives of this study were to evaluate the effect of marination on marinade uptake of chicken carcasses and to determine the meat quality of carcass parts. In total, 45 eviscerated chicken carcasses were divided into three marinating treatments: no marination, marination in water, marination in non-phosphate and low-salt solution (NPLS). The study showed that the marinade uptake of chicken carcasses was higher than $4.0 \%$ for NPLS marination and than 3.5\% for water marination when compared with the non-marinated treatment. However, raw chicken meat yield after cut-up was not significantly different $(p \geq 0.05)$ among treatments. Carcasses marinated in NPLS solution presented higher water-holding capacity (WHC). The results showed that NPLS marination may reduce cooking loss and expressible water of chicken meat after cooking. Based on the Warner-Bratzler Shear (WBSF) results, NPLS marination had a stronger effect on textural quality of cooked breast meat than thighs and drumsticks. However, no significant differences of texture profile analysis (TPA) parameters were observed $(p \geq 0.05)$. In the sensory evaluation, NPLS marination influenced the sensory quality of cooked meat, particularly texture and appearance attributes, but not the taste and aftertaste attributes of cooked meat. It is concluded that NPLS marination effectively increased carcass weight, despite its effects on meat quality varied according to the anatomical location of the parts.

\section{INTRODUCTION}

In the market, chicken meat is sold as whole carcasses or as parts (whole breast, deboned fillets, wings, drumstick, thighs, whole leg, etc.). However, weight loss due to cut up leads to economic losses for poultry processors. As chicken products are sold by weight, any weight loss is economically undesirable. In addition, carcass cut up may influence the appearance of raw meat and cooked meat quality, such as tenderness, juiciness, firmness and appearance (Martens et al., 1982). Bowker \& Zhuang (2013) reported that weight loss during cut-up not only reduced the yield and meat quality of fresh meat, but also had impaired meat functional properties during the production of further processed poultry products.

Several Thai poultry companies currently prefer to sell or to export eviscerated whole chicken carcasses, as it saves processing time and cut-up labor and machine costs. Therefore, studies on processes to minimize carcass weight loss and to enhance carcass quality during cut-up are needed.

The process of tumbling marination is commonly applied by processing companies to improve the quality of chicken meat products (Sen et al., 2005; Alvarado \& McKee, 2007), as it increases both water 
U-chupaj J, Malila Y, Petracci M, Benjakul S, Visessanguan W Effect of Tumbling Marination on Marinade Uptake of
Chicken Carcass and Parts Quality absorption and improves the texture of meat after marination. Maki \& Froning (1986) evaluated the tumbling marination of whole turkey carcasses, and reported increased carcass yield and reduced breast meat cooking losses. Siegel et al. (1978) had previously shown better water binding quality and lower cooking loss when hams were submitted to tumbling.

In our previous studies, we observed that the quality of normal and abnormal chicken breast meat was improved when tumbled with a non-phosphate and low-sodium salt (NPLS) additive combination (U-chupaj, 2016). Due to the limited information on tumbling marination of eviscerated chicken carcasses, the objectives of this study were to evaluate the effect of tumbling combined with a marinade consisting of a NPLS additive solution on carcass marinade uptake, and its impact on parts yield, water holding capacity, and cooked meat quality.

\section{MATERIALS AND METHODS}

\section{Sample collection}

Forty-five eviscerated chicken carcasses (Ross 308 male, $50 \pm 2$ days old, $3.2 \pm 0.1 \mathrm{~kg}$ average body weight) were obtained from Sun Food International (SFI) Co., Ltd., Saraburi, Thailand. All birds were fasted for 12 h, weighed, manually sacrificed by neck cutting, and bled for $3 \mathrm{~min}$. Carcasses were scalded at $70{ }^{\circ} \mathrm{C}$ for 2 min, plucked in a rotary drum for $30 \mathrm{~s}$, and eviscerated according to the industrial standard practice. Carcasses were placed in a tumble chiller, where they remained immersed in iced water at approximately $0.6{ }^{\circ} \mathrm{C}$ for $75 \mathrm{~min}$. After chilling, chicken carcasses were placed in coolers and aged at $4 \pm 1^{\circ} \mathrm{C}$ up to $6 \mathrm{~h}$ postmortem before further processing.

\section{Marination procedure}

On the day after slaughter (6h postmortem), eviscerated chicken carcasses were individually weighed and assigned to one of the three treatment groups (15 carcasses per treatment): not marinated, water marination, or and NPLS marination. The eviscerated carcasses were placed into a VMS-37-529 tumbler (Globus Laboratories Inc, Vienna, Austria) and marinated by tumbling either in water or in a non-phosphate low salt (NPLS) additive marinade solution containing 7.2\% $(\mathrm{w} / \mathrm{v})$ of potassium bicarbonate, potassium chloride, and sorbitol (U-chupaj, 2016) at acarcass to marinade ratio of 100:50 w/W. The marination ware operated under non-vacuum conditions at $2 \pm 1{ }^{\circ} \mathrm{C}$ for $30 \mathrm{~min}$ and $7 \pm 1 \mathrm{rpm}$ speed. The experiment was performed in 3 batches ( 5 carcasses per batch).

\section{Carcass and parts meat quality}

The effects of the marinating process on carcass marinade uptake and meat quality of the parts were evaluated and compared among the treatments. Carcass marinade uptake was determined after marination, and raw parts yield and drip loss were investigated after cut-up. Three main carcass parts (breast, thighs, and drumsticks) were skinned, deboned, and cooked, after which cooking loss, expressible water, texture, and sensory properties were determined.

\section{Marinade uptake}

Immediately after tumbling marination, each marinated carcass was hanged to drain marinade excess at $10{ }^{\circ} \mathrm{C}$ for $30 \mathrm{~min}$ and weighed again. Marinade uptake was calculated based on carcass weight of before marination $\left(W_{1}\right)$ and its weight after marination $\left(W_{2}\right)$, according to the equation:

Marinade uptake $(\%)=\left[\left(W_{2}-W_{1}\right) / W_{1}\right] \times 100$

\section{Parts yield}

After $1 \mathrm{~h}$ marination (8h postmortem), each carcass was manually cut with a knife into five parts: breast meat with fillets, wings, thighs, drumsticks, and neck and back (Figure 1). All parts were skin-on and bone-

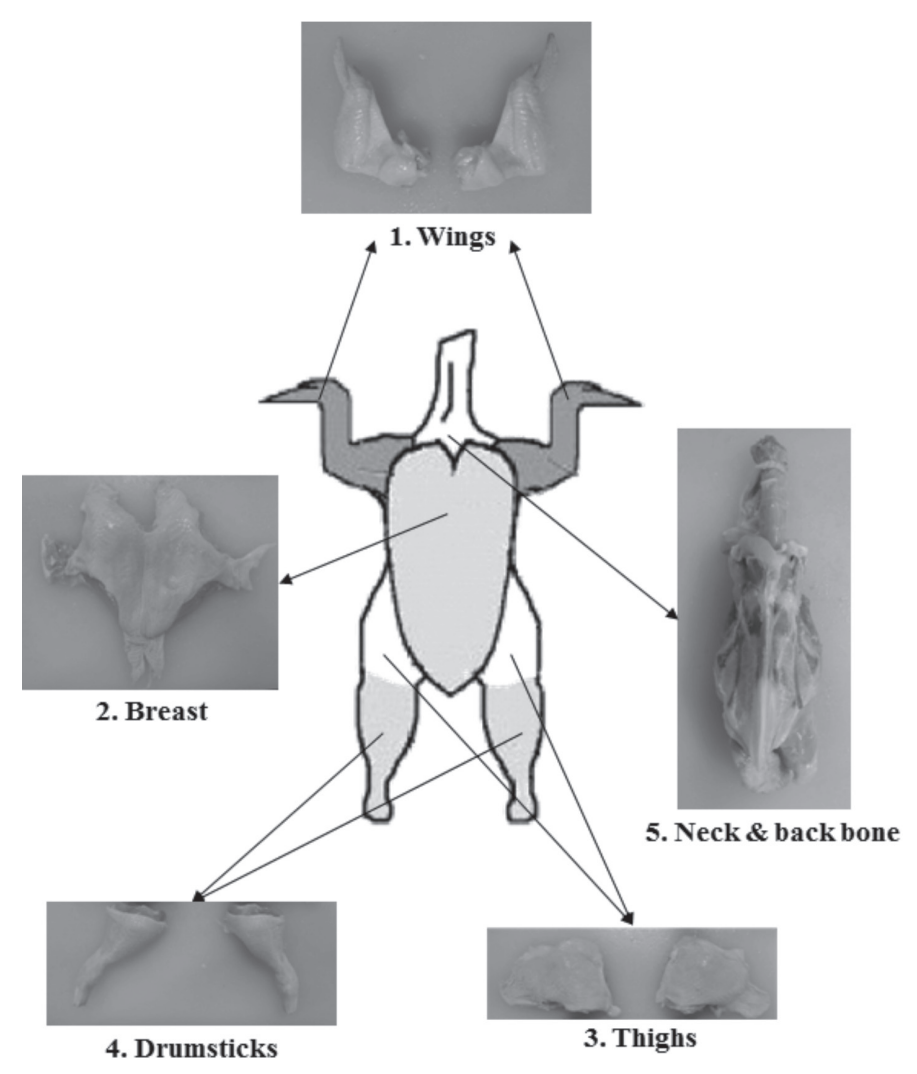

Figure 1 - Carcass parts 
in after cut-up. Parts weights were measured and recorded per individual carcasses. Care was taken not to mix the parts with those of other carcasses. Parts yield was calculated as the ratio between part weight (PW) and carcass weight (CW), according to the equation:

$$
\text { Cut-up yield }(\%)=\frac{P W}{C W} \times 100
$$

\section{Drip loss}

The three carcass parts (breasts, thighs and drumsticks) were used to determine drip loss. All parts were individually weighed, packed, and stored at $4 \pm$ $1{ }^{\circ} \mathrm{C}$ for $24 \mathrm{~h}$. Then, the difference of meat weight before $\left(W_{3}\right)$ and after $24 \mathrm{~h}$ storage $\left(W_{4}\right)$ was recorded, and expressed as drip loss percentage (Petracci \& Baeza, 2010).

$$
\text { Drip loss }(\%)=\left[\left(W_{3}-W_{4}\right) / W_{3}\right] \times 100
$$

\section{Cooking loss}

Before cooking, breast, thighs and drumsticks were skinned and deboned using the method of Hamm (1981). The parts were individually vacuum-packed, placed in water bath (Model WNE 22, Memmert, Inc., Schwabach, Germany) maintained at $95^{\circ} \mathrm{C}$, and cooked until internal temperature reached $80^{\circ} \mathrm{C}$. Internal meat temperature was monitored throughout the cooking process using a thermocouple inserted into the thickest part of the meat. After cooking, the individual packs were cooled on ice water, drained, blotted dry, and weighed to calculate the cooking loss:

$$
\text { Cooking loss }(\%)=\left[\left(W_{4}-W_{5}\right) / W_{4}\right] \times 100
$$

Where: $W_{4}=$ Weight before cooking, and $W_{5}=$ Weight after cooking.

\section{Expressible water}

Expressible water was measured according to the method of Liu et al. (2011) with slight modifications. Each part of the cooked meat samples (breast, thighs and drumsticks) was cut into two $15 \times 15 \times 15 \mathrm{~mm}$ cubes to obtain 30 cubes per treatment. The cubes were then weighed, placed between two pieces of Whatman filter paper No. 1 (Whatman International Ltd., Maidstone, England). Cubes were submitted to compression at $70 \%$ strain for $60 \mathrm{~s}$ using a TAHDi texture analyzer (Stable Micro Systems Ltd, UK) equipped with a 50-mm cylinder aluminum probe at room temperature, removed and weighed again. Expressible water content was calculated and expressed as percentage of sample weight as follows:
Expressible water $(\%)=\left[\left(w t_{1}-w t_{2}\right) / w t_{1}\right] \times 100$

Where: $w t_{1}=$ Weight before compression and $w t_{2}=$ Weight after compression

\section{Cooked meat texture}

The texture of cooked chicken meat (breast, thighs and drumsticks) was determined by the WarnerBratzler shear force (WBSF) and texture profile analysis (TPA) methods. Cooked meat sample was cut parallel to muscle fibers into four $10 \times 20 \times 10 \mathrm{~mm}$ strips for WBSF (60 strips per treatment) and two $15 \times 15 \times 15$ $\mathrm{mm}$ cubes for TPA (30 cubes per treatment).

WBSF: Cooked meat strips were sheared perpendicularly to the fiber direction using a TA-HDi texture analyzer equipped with a Warner-Bratzler shear blade with a $25-\mathrm{kg}$ loading cell. The instrument parameters were set as follows: $1 \mathrm{~mm} / \mathrm{s}$ test speed, 25 to $30 \mathrm{~mm}$ working distance, and $0.2 \mathrm{~N}$ trigger force. The actual cross-sectional area at the shearing point indicates WBS force $(\mathrm{N})$, while work of shear $(\mathrm{N} \mathrm{mm})$ represents the area under the force deformation curve. Both parameters were automatically calculated by Texture Expert software, version 1.0 (Stable Micro Systems, UK).

TPA: Cooked meat cubes were double-compressed to $40 \%$ of their initial height using a $25-\mathrm{kg}$ loading cell connected to a 50-mm cylinder aluminum probe using TA-HDi texture analyzer. Test conditions were: $1 \mathrm{~mm} / \mathrm{s}$ probe velocity, 1 s holding time, and $0.1 \mathrm{~N}$ trigger force. The TPA parameters hardness $(\mathrm{N})$, springiness (ratio), cohesiveness (ratio), gumminess $(\mathrm{N})$, and chewiness $(\mathrm{N} \times \mathrm{mm})$ were calculated from the force-time curves recorded for each sample using Texture Expert software version 1.0 (Bourne, 1976; Herrero et al., 2007).

\section{Sensory evaluation}

Sensory meat characteristics were evaluated by 30 in-house panelists. All panelists were selected from the staff members of the SFI, who had from 2 to 10 years of experience working with cooked chicken meat products. After cooking, meat samples were cut into $1.5-\mathrm{cm}$ cubes and kept warm until served at 55 ${ }^{\circ} \mathrm{C}$. Once the panelists tasted the samples, they were asked to assess the intensity of sensory attributes from $1=$ low to $9=$ high intensity. The sensory attributes and definitions used by the panel to evaluate cooked meat are detailed in Table 1 (Lyon et al., 2004; Zhuang \& Savage, 2012). 
U-chupaj J, Malila Y, Petracci M, Benjakul S, Visessanguan W

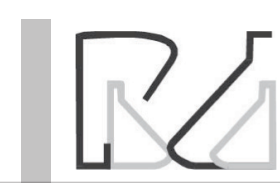

Effect of Tumbling Marination on Marinade Uptake of Chicken Carcass and Parts Quality
Table 1 - Sensory attributes and definitions

\begin{tabular}{|c|c|}
\hline Attributes & Definitions \\
\hline \multicolumn{2}{|c|}{ Overall appearance } \\
\hline Moistness & Amount of moisture on surface of cooked meat \\
\hline Surface color & The intensity of the surface color of cooked meat \\
\hline \multicolumn{2}{|l|}{ Flavor } \\
\hline Metallic & The smell of the inside of a tin can \\
\hline Cooked meat & Aroma associated with boiled meat, soup, stock \\
\hline \multicolumn{2}{|r|}{$x^{2}$} \\
\hline Sweetness & Sugar and high potency sweeteners \\
\hline Saltiness & Sodium salts, especially sodium chloride \\
\hline Bitterness & Caffeine or quinine \\
\hline \multicolumn{2}{|l|}{ Texture } \\
\hline Firmness & $\begin{array}{l}\text { Force to compress the sample between the molars } \\
\text { during first } 2 \text { bites }\end{array}$ \\
\hline Chewiness & $\begin{array}{l}\text { Amount of work required to chew the sample to } \\
\text { the point of swallow }\end{array}$ \\
\hline Juiciness & $\begin{array}{l}\text { Amount of moisture coming from the sample } \\
\text { during mastication }\end{array}$ \\
\hline \multicolumn{2}{|l|}{ Aftertaste } \\
\hline Astringency & $\begin{array}{l}\text { Chemical feeling factor on tongue or other surface } \\
\text { of oral cavity described as dryand puckering; } \\
\text { associated with tannins or alum }\end{array}$ \\
\hline Acceptability & A general feeling on the basis of each attribute \\
\hline
\end{tabular}

\section{Statistical analysis}

The results were subjected to analysis of variance (ANOVA), and means were compared by Duncan's multiple range test (Steel \& Torrie, 1980) at a significance level of $p<0.05$. The statistical analysis was performed by using the Statistical Package for the Social Sciences (SPSS Inc., Chicago, III., USA).

\section{RESULTS AND DISCUSSION}

\section{Carcass marinade uptake and parts yield}

The effects of marination on carcass marinade uptake and parts yield after cutting up are presented in Table 2. NPLS marination promoted higher carcass marinade uptake compared with water marination $(p<0.05)$, indicating that the additive included in the marinade solution increased carcass water absorption. These results are in agreement with previous studies, which reported about 4 to $8 \%$ water absorption in poultry carcasses immersed in marinades (Veerkamp, 1990; Young \&Smith 2004; Huezo et al., 2007 Jeong et al., 2011; Demirok et al., 2013). The increase in carcass weight of both marinated treatments was probably due to water absorption during marination. Sanders (1969) also showed that when agitation was provided during marination, the water penetration between the skin and the muscle was significantly increased. This indicates that tumbling can increase chicken carcass water absorption due to the mechanical force of agitation. However, several European countries have established limit of $6 \%$ for carcass water uptake up after marination or immersion chilling (EC Commission Regulation, 2008).

Relative to total weight gain, breast, thigh and drumstick meat yields were not significantly affected by the marinating treatments $(p \geq 0.05)$. It is presumed that penetration of marinated solution across the skin of each part may have been limited. Moreover, the marinade solution may not infiltrate from the inside of eviscerated carcass into meat because bones and connective tissue may prevent marinade absorption by the meat.

\section{Drip loss, cooking loss and expressible water of chicken meat}

Drip losses of the breast, thighs and drumsticks are depicted in Figure 2a. Thighs presented higher drip loss, followed by breasts and drumsticks. Unexpectedly, samples from both marinated treatments exhibited a greater drip loss than the non-marinated samples, possibly because the water absorbed by the marinated samples was lost during storage. High drip loss is undesirable for both processors and consumers. For poultry processors, high drip loss reduces product yield, impairing its functionality during the production of further processed chicken products (Bowker \& Zhuang, 2013). Excessive drip loss results in an unappealing accumulation of moisture in the packages at retail, and

Table 2 - Effect of marination on carcass marinade uptake and cut-up yield

\begin{tabular}{|c|c|c|c|c|c|}
\hline \multirow[t]{2}{*}{ Parameter } & \multicolumn{3}{|c|}{ Treatment } & \multirow[t]{2}{*}{$\mathrm{SEM}^{+}$} & \multirow[t]{2}{*}{$p$-value } \\
\hline & Non marination & Water marination & NPLS marination & & \\
\hline Marinade uptake (\%) & $0.00^{c}$ & $3.51^{\mathrm{b}}$ & $4.09^{a}$ & 0.29 & $<0.001$ \\
\hline \multicolumn{6}{|l|}{ Cut-up yield (\%) } \\
\hline Breast & 32.98 & 32.54 & 33.05 & 0.27 & 0.705 \\
\hline Wings & 9.80 & 9.67 & 9.52 & 0.06 & 0.118 \\
\hline Thighs & 18.58 & 18.19 & 18.58 & 0.18 & 0.623 \\
\hline Drumsticks & 12.19 & 12.36 & 11.72 & 0.14 & 0.183 \\
\hline Neck and back bone & 26.35 & 26.93 & 26.70 & 0.20 & 0.490 \\
\hline
\end{tabular}

Different superscripts within the same row indicate significant differences $(p<0.05)$.

${ }^{+}$Standard errors of means. 
loss of tenderness when the products are cooked, both of which are considered unacceptable by consumers.

Figure $2 \mathrm{~b}$ illustrates chicken meat cooking loss. All NPLS marinated parts presented significantly lower cooking loss compared with water-marinated and non-marinated samples $(p<0.05)$. Water-marinated samples presented the highest cooking loss, except for drumsticks, which cooking loss was statistically similar to that of non-marinated samples ( $p \geq 0.05)$.

In terms of expressible water percentage (Figure $2 c)$, lower values were obtained in breast samples marinated with NPLS presented compared with those

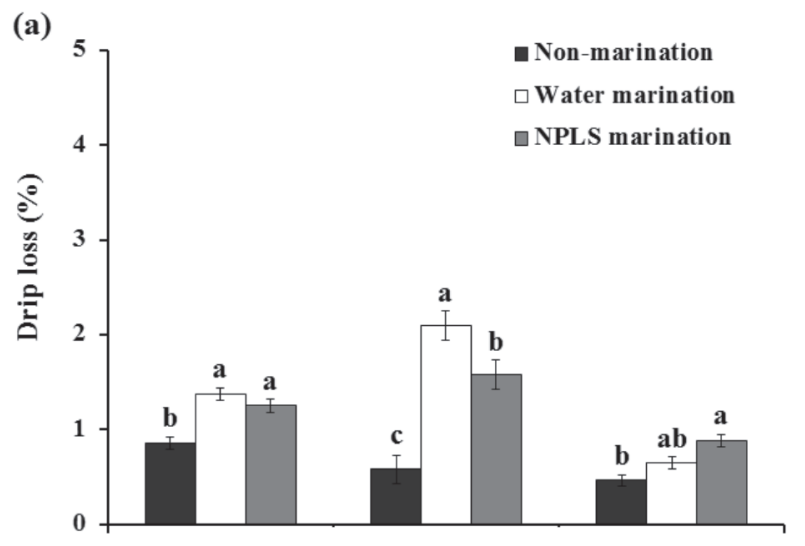

(b)

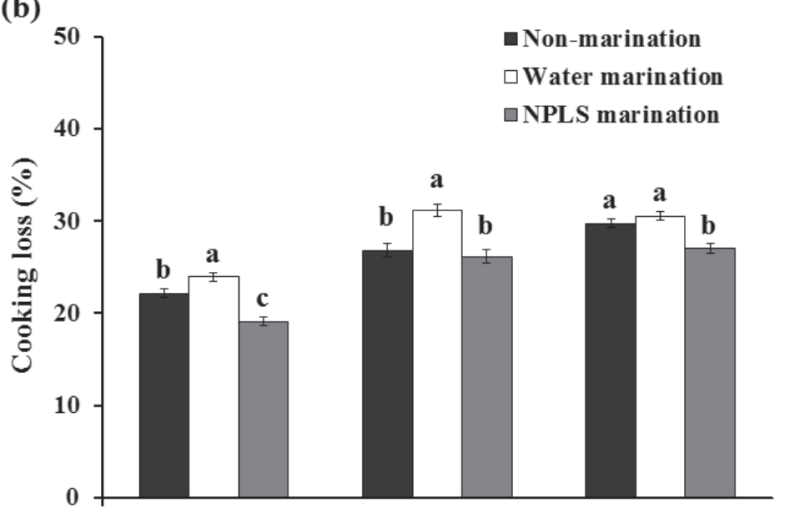

(c)

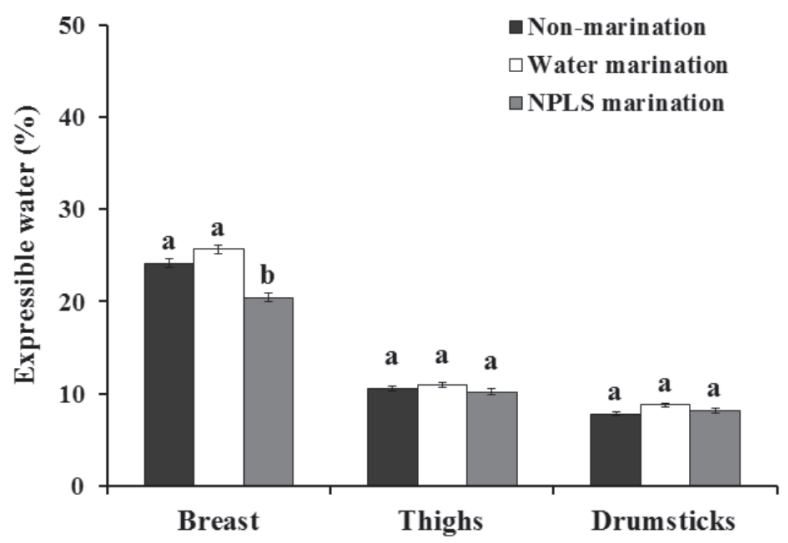

Figure 2 - Drip loss (a), cooking loss (b) and expressible water (c) of chicken meat from three treatments: non-marination ( $\square$ ), water marination $(\square)$ and NPLS marination ( $\square$ ). Different letters indicate significant differences among treatments $(p<0.05)$. marinated in water or not marinated, but the treatments had no effect on thigh or drumstick samples. These results indicate that the effects of marination on this parameter depend on the anatomical location where meat samples were taken. This result was in agreement with van den Berg et al. (1963) and Swanson et al. (1964), who evaluated the effect of muscle location on the water retention properties of chicken meat. Those authors reported that dark meat presented lower ability to retain water than white meat, as indicated by the higher weight loss of dark meat after cooking, and may be explained by differences in the chemical composition, structure, morphology and fiber type of these muscles. Marination with NPLS increases cooked meat WHC as it reduces loss and expressible water percentage, as well as increases meat after cooking, particularly in chicken breast meat.

\section{Cooked meat texture}

The textural quality of cooked chicken meat is presented in Table 3. The effects of marination were more pronounced on cooked breast meat than on thighs or drumsticks. The lowest shear force was observed in both marinated breast samples when compared with non-marinated samples $(p<0.05)$. This is probably due to the effect of mechanical force of tumbling, which disrupts muscle cells. The lowest work of shearing was also observed in the NPLS marinated samples, indicating that NPLS marination was effective to enhance the tenderness of cooked chicken breast meat. However, TPA parameters of the cooked chicken breast meat samples were not affected by the treatments $(p \geq 0.05)$. Furthermore, the WBSF and TPA results showed that the textural properties of cooked thigh and drumstick meat samples were not significantly different among three treatments $(p \geq 0.05)$. This indicates that the marination treatments had weak effects on the textural quality of both meat portions.

\section{Sensory characteristics of cooked chicken meat}

Figure 3 illustrates the effects of marination on cooked chicken meat quality, including appearance, flavor, taste, texture, after taste, and meat acceptability.

For breast meat (Figure 3a), the results showed noticeable differences in cooked meat flavor, firmness, juiciness, astringency, and acceptability attributes. The panelists gave the highest acceptability score for the non-marinated sample, although it received the lowest flavor score. The lowest acceptability score was observed in the water-marinated sample, which was probably due to its higher astringency score. Moreover, the lowest 
Table 3 - Textural properties of cooked chicken meat

\begin{tabular}{|c|c|c|c|c|c|c|c|c|c|c|c|c|c|c|c|}
\hline \multirow[t]{3}{*}{ Parameter } & \multicolumn{5}{|c|}{ Treatment } & \multicolumn{5}{|c|}{ Treatment } & \multicolumn{5}{|c|}{ Treatment } \\
\hline & A & $B$ & $C$ & $\mathrm{SEM}^{+}$ & p-value - & A & B & $C$ & $\mathrm{SEM}^{+}$ & p-value - & A & $B$ & $C$ & $\mathrm{SEM}^{+}$ & $p$-value \\
\hline & \multicolumn{5}{|c|}{ Breast } & \multicolumn{5}{|c|}{ Thighs } & \multicolumn{5}{|c|}{ Drumsticks } \\
\hline \multicolumn{16}{|l|}{$\begin{array}{l}\text { Warner-Bratzler } \\
\text { shear }\end{array}$} \\
\hline Shear force $(N)$ & $34.61^{a}$ & $29.67^{b}$ & $27.02^{b}$ & 0.81 & $<0.001$ & 21.18 & 19.73 & 19.74 & 0.79 & 0.704 & 14.46 & 13.43 & 13.46 & 0.64 & 0.765 \\
\hline $\begin{array}{l}\text { Work of } \\
\text { shearing } \\
\text { (N×mm) }\end{array}$ & $259.85^{a}$ & $247.58^{a}$ & $184.70^{\mathrm{b}}$ & 8.82 & $<0.001$ & 159.20 & 147.20 & 156.34 & 6.57 & 0.762 & 121.70 & 119.50 & 130.46 & 4.52 & 0.589 \\
\hline \multicolumn{16}{|l|}{$\begin{array}{l}\text { Texture profile } \\
\text { analysis }\end{array}$} \\
\hline Hardness (N) & 27.11 & 27.24 & 25.61 & 0.58 & 0.451 & 16.04 & 16.40 & 15.88 & 0.45 & 0.894 & 14.63 & 13.58 & 13.48 & 0.45 & 0.521 \\
\hline $\begin{array}{l}\text { Springiness } \\
\text { (ratio) }\end{array}$ & 0.66 & 0.66 & 0.66 & 0.00 & 0.729 & 0.63 & 0.62 & 0.62 & 0.01 & 0.673 & 0.65 & 0.67 & 0.66 & 0.01 & 0.737 \\
\hline $\begin{array}{l}\text { Cohesiveness } \\
\text { (ratio) }\end{array}$ & 0.45 & 0.44 & 0.43 & 0.00 & 0.367 & 0.35 & 0.37 & 0.35 & 0.01 & 0.479 & 0.38 & 0.38 & 0.38 & 0.01 & 0.982 \\
\hline Gumminess (N) & 12.12 & 11.99 & 11.16 & 0.31 & 0.388 & 5.80 & 5.93 & 5.59 & 0.23 & 0.839 & 5.51 & 5.17 & 5.15 & 0.21 & 0.739 \\
\hline $\begin{array}{l}\text { Chewiness } \\
(\mathrm{N} \times \mathrm{mm})\end{array}$ & 7.97 & 7.93 & 7.40 & 0.21 & 0.475 & 3.71 & 3.70 & 3.49 & 0.17 & 0.842 & 3.56 & 3.53 & 3.40 & 0.16 & 0.92 \\
\hline
\end{tabular}

Where: $A$ = non-marination, $B=$ water marination, $C=N P L S$ marination.

Different superscripts within the same row indicate significant differences $(p<0.05)$.

Standard errors of means.

firmness and the highest juiciness scores were given to the NPLS-marinated sample, suggesting that it was more tender and was juicier than the other samples.

For thigh meat (Figure 3b), panelists gave lower acceptability score for the non-marinated sample, while no differences were observed between the watermarinated and NPLS-marinated samples. This was probably due to the higher score for metallic flavor and astringent taste given to the non-marinated sample. In addition, the water-marinated sample was given a lower score for surface moisture than other cooked meat samples. The higher cooking water loss of water-marinated samples (Figure $2 b$ ) resulted in lower moisture content in the cooked meat, resulting in the lower appearance score given by the panelist. As for the texture attributes, the higher firmness and juiciness scores, and the lower chewiness scores given to the NPLS-marinated samples indicate that these samples were more tender and juicier than the other samples.

For drumstick meat (Figure 3c), NPLS-marinated samples received higher scores for surface moisture and color attributes, indicating that NPLS marination can improve the appearance of cooked drumstick meat. The water-marinated sample received lower flavor and sweetness scores. This may be due to the loss meat flavor and taste during cooking. However, the acceptability score of drumsticks submitted to the three evaluated treatments was not different. This was probably caused by the small differences in metallic flavor and astringent attributes, among others. Based on the sensory results, NPLS marination had a stronger influence on texture, despite the lack of differences obtained in the TPA analysis. Moreover, NPLS marination may enhance appearance attributes, and has lower on cooked meat taste and aftertaste attributes, while the cooked chicken meat submitted to water marination presented worse sensory quality.

\section{CONCLUSIONS}

The findings of this study indicated that NPLS marination may be used to enhance the quality of chicken carcasses after chilling. It may increase marinade uptake by the eviscerated chicken carcass and improve chicken meat quality after cut-up. Lower cooking loss, expressible water, and better texture were observed in the breast than in the thighs and drumsticks. However, this process should be further investigated at commercial scale to allow its potential use in industrial processing plants.

\section{ACKNOWLEDGEMENTS}

This work was financially supported by a grant from The Thailand Research Fund, under the Royal Golden Jubilee Ph.D. Program, to Juthawut U-chupaj (Grant No. PHD/0282/2551). The authors would like to thank Graduate School of Prince of Songkla University and National Center for Genetic Engineering and Biotechnology (BIOTEC), Thailand for the financial support and experimental facilities, and Sun Food International Co., Ltd. for supplying chicken meat used throughout the study. 


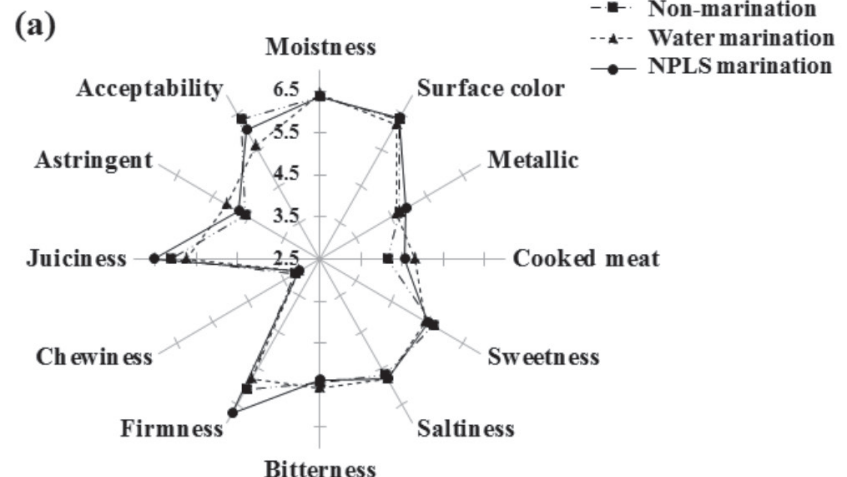

(b)

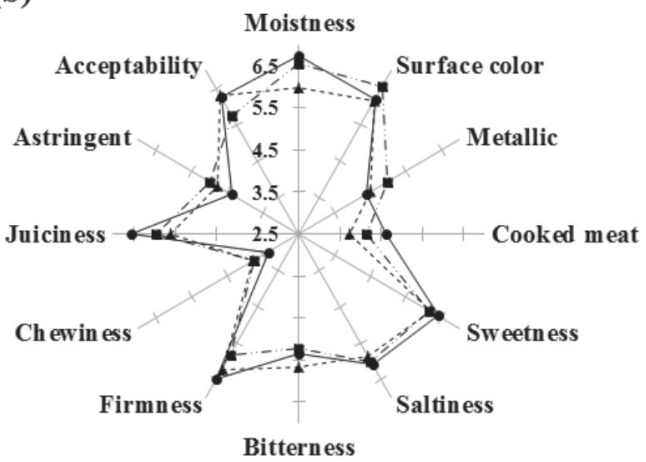

(c)

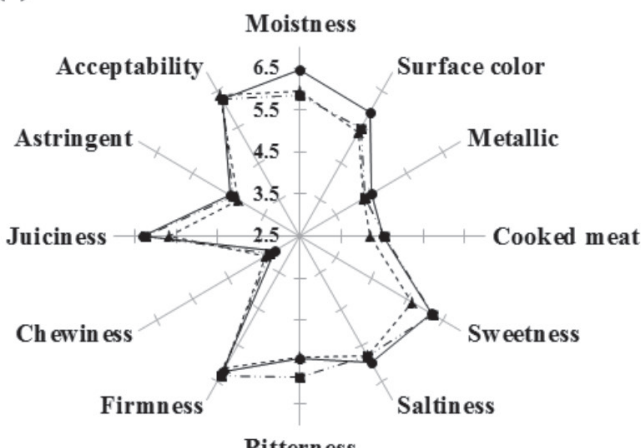

Figure 3 - Spider web of mean values of 12 sensory attributes of cooked breast (a), thigh (b), and drumstick (c) meat samples that were not marinated and marinated with water or with NPLS.

\section{REFERENCES}

Alvarado C, McKee S. Marination to improve functional properties and safety of poultry meat. The Journal of Applied Poultry Research 2007;16(1):113-120

Bourne MC. Texture profile analysis. Food Technology1978;32:62-65.

Bowker BC, Zhuang $\mathrm{H}$. Relationship between muscle exudate protein composition and broiler breast meat quality. Poultry Science 2013;92(5);1385-1392.

Commission Regulation EC. Laying down detailed rules for the application of Council Regulation (EC) No 1234/2007 as regards the marketing standards for poultry meat. Official Journal of the European Union 2008; p.46-87.

Demirok E, Veluz G, Stuyvenberg WV, Castañeda MP, Byrd A, Alvarado CZ. Quality and safety of broiler meat in various chilling systems. Poultry Science 2013;92(4):1117-1126.
Hamm D. Unconventional meat harvesting [abstr]. Poultry Science 1981;60(Suppl1):1666

Herrero AM, Ordóñez JA, de Avila R, Herranz B, de la Hoz L,Cambero MI. Breaking strength of dry fermented sausages and their correlation with texture profile analysis (TPA) and physico-chemical characteristics. Meat Science 2007:77(3);331-338.

Huezo R, Smith DP, Northcutt JK, Fletcher DL. Effect of immersion or dry air chilling on broiler carcass moisture retention and breast fillet functionality. The Journal of Applied Poultry Research2007;16(3):438-447.

Jeong JY, Janardhanan KK, Booren AM, Karcher DM, Kang I. Moisture content, processing yield, and surface color of broiler carcasses chilled by water, air, or evaporative air. Poultry Science2011;90(3):687-693.

Liu BY, Wang ZY, Yang HM, Wang JM, Xu D, Zhang R, et al. Influence of rearing system on growth performance, carcass traits, and meat quality of Yangzhou geese. Poultry Science 2011;90(3);653-659.

Lyon BG, Smith DP, Lyon CE, Savage EM. Effects of diet and feed withdrawal on the sensory descriptive and instrumental profiles of broiler breast fillets. Poultry Science2004;83(2):275-281.

Maki AA, Froning GW. Effect on the quality characteristics of turkey breast muscle of tumbling whole carcasses in the presence of salt and phosphate. Poultry Science1987;66(7):1180-1183.

Martens H, Stabursvik E, Martens M. Texture and colour changes in meat during cooking related to thermal denaturation of muscle protein. Journal of Texture Studies 1982;13(3):291-309

Petracci M, Baéza E. Harmonization of methodologies for the assessment of poultry meat quality features. World's Poultry Science Journal 2011;68(1):137-153.

Sanders $\mathrm{DH}$. Fluorescent dye tracing of water entry and retention in chilling of broiler chicken carcasses. Poultry Science 1969;48(6);2032-2037.

Sen AR, Naveena BM, Muthukumar M, Babji Y, Murthy TRK. Effect of chilling, polyphosphate and bicarbonate on quality characteristics of broiler breast meat. British Poultry Science 2005;46(4):451-456.

Siegel DG, Theno DM, Schmidt GR, Norton HW. Meat massaging: the effects of salt, phosphate and massaging on cooking loss, binding strength and exudate composition in sectioned and formed ham. Journal of Food Science 1978;43(2):331-333.

Steel RGD, Torries JH. Principle and procedure of statistic: a biomaterial approach. New York: McGrow-Hill; 1980

Swanson MH, Carlson CW, Fry JL. Factors affecting poultry meat yields. Minnesota: Agricultural Experiment Station; 1964.

U-chupaj J. Textural characteristics of capons and development of mixed additives for meat quality improvement. [dDissertation]. Songkhla (THA): Prince Songkla University;2015.

Van den Berg L, Khan AW, Lentz CP. Biochemical and quality changes in chicken meat during storage at above-freezing temperatures. Food Technology 1963;17:91.

Veerkamp $\mathrm{CH}$. Chilling of poultry and poultry products. In: Gormley TR, editor. Chilled foods: the state of the art. New York: Elsevier Applied Science; 1990. p.147-158.

Young LL, Smith DP. Moisture retention by water- and air-chilled chicken broilers during processing and cutup operations. Poultry Science 2004;83(1):119-122.

Zhuang $H$, Savage EM. Effects of fillet weight on sensory descriptive flavor and texture profiles of broiler breast meat. Poultry Science 2012:91(7):1695-1702 
